\author{
Sustinere \\ Journal of Environment and Sustainability \\ Volume 4 Number 3 (2020) 172-188 \\ Print ISSN: 2549-1245 Online ISSN: 2549-1253 \\ Website: https://sustinerejes.com E-mail: sustinere.jes@iain-surakarta.ac.id
}

\title{
RESEARCH PAPER \\ Ecomusicology: A socioecological dimension towards acoustically sustainable residential buildings
}

\author{
Peter Uchenna Okoye ${ }^{*}$, Kevin Chuks Okolie ${ }^{1}$, Christian Ifeanyi Ohaedeghasi ${ }^{1}$, \\ Chukwuemeka $\mathrm{Ngwu}^{2}$ \\ ${ }^{1}$ Department of Building, Nnamdi Azikiwe University, Awka, Nigeria \\ ${ }^{2}$ Department of Quantity Surveying, Nnamdi Azikiwe University, Awka, Nigeria \\ Article history: \\ Received 1 August 2020 | Accepted 24 November 2020 | Available online 31 December 2020
}

\begin{abstract}
This study examined the socioecological roles of music sounds towards achieving acoustically sustainable residential building. The study adopted a survey research approach where questionnaires were distributed to the occupants of different types of residential buildings in three urban cities of Anambra State Nigeria. The survey data were analysed using Statistical Package for the Social Science (SPSS) Software. The results revealed that music plays significant roles towards acoustically sustainable building performance with the overall average mean score index of 4.36; and a range of 3.64 to 4.87. But the three most outstanding roles played by music towards acoustically sustainable building performance were: Enabling pleasant sound environment (4.87), improving quality of relaxation and resting (4.83), and increasing acoustic comfort and satisfaction (4.79). The result of one-way ANOVA revealed that music sounds significantly influence acoustical sustainability performance of residential buildings (p-value (.000) < $\alpha(0.05)$; F-ratio (148.377) > F-critical (3.020)); and that there was no significance difference between opinions of residents of the three urban cities in this regard (p-value (0.713) > $\alpha(0.05)$; F-ratio (0.338) < F-critical (3.020)). This study therefore, canvassed for integration of music principles and acoustics into sustainable building design processes as a way of achieving a sustainable building.
\end{abstract}

Keywords: acoustics; ecomusicology; music; residential building; socioecological dimension; sustainability

\section{Introduction}

The roles of music have been recognised across cultures in religion, celebration, social activities, cultural activities, and as well as satisfying the desire for aesthetic pleasure, entertainment, and social situations (Jiang et al., 2019). Proper sound condition in a residential building is therefore, a major characteristic of an acoustically sustainable building (Vardaxis et al., 2018). Jahangeer (2019) argued that there is a need for integration of architectural measures and aural environment in order to improve the comfort of residential buildings. Music sound therefore, contributes substantially to the acoustic soundscape of a residential environment.

${ }^{*}$ Corresponding author: E-mail: pu.okoye@unizik.edu.ng DOI: https://doi.org/10.22515/sustinere.jes.v4i3.123 
Unfortunately, studies in the field of building acoustics, psychoacoustics and built environment that directly dealt with music acoustics and residential building sustainability are sparse, tangential and partial (Aletta et al., 2017; Aletta \& Astolfi, 2018; Jahangeer, 2019; Meng et al., 2018; Reinten et al., 2017; Vardaxis et al., 2018; Vargas Vera e al., 2019). Studies that directly linked music and built environment are even fewer (Morimoto, 2017). However, the main goal of soundscape design and acoustic comfort improvement is not only to reduce relatively unpleasant sounds (such as noise), but also to design and enable a relatively pleasant sound environment (Taghipour et al., 2019). A good acoustic environment is absolutely essential to maintaining a high level satisfaction and moral health among residents (Zhisheng et al., 2007).

Debate over the relationship between music and nature has increased since the emergent of the new concept called "ecomusicology" which was dated back to the nineteenth century (Bendrups et al., 2013; Snyder, 2019). In the contemporary society, the current global discourses on diversity and ecology has been amplified by introducing sustainability concept into the ongoing discussion (A. Allen \& Dawe, 2016; Bendrups et al., 2013; P. Petocz, 2019). According to Jodouin (2018), this is a result of reacting to the increased environmental crises of the twentyfirst century. Therefore, sustainability and ecomusicology have brought up another concept of soundscape to awaken people to their natural acoustic surroundings in an increasingly noisy world. Fundamentally, music and all sounds are considered in vibrational terms as transferable energy, which impinges upon our body and our senses (Eidsheim, 2015). As an energy that pulsates through and across a medium; the structural interpretation and aesthetic conceptualisation of music occur when the sound has been processed, decoded, and interpreted in our nervous system (Reybrouck et al., 2019).

Music industry no doubt has potential for social and cultural sustainability. The roles of music in the transition towards social and cultural sustainability have been recognised (Barbaroux et al., 2019; Hallam, 2015; Hawkes, 2001; Martin, 2017; van der Hoeven \& Hitters, 2019; Wolcott, 2016). This is seen in the form of social equity, environmental responsibility, cultural heritage and economic viability (Hawkes, 2001; Petocz et al., 2014). Music also embraces a multilevel interconnection with organism, population, and community so as to ensure cultural and ecological sustainability (Peter Petocz et al., 2014; Titon, 2009b), to sustain urban and rural community building as well as the healing process of individuals and communities (Ogunrinade, 2015), and can act as biocultural resource that is renewable (Titon, 2009a). Furthermore, music especially live music is a source of tourist attraction, offers a sense of belonging and contributes to a thriving cultural environment (Martin, 2017). Aside skills development, Hallam (2015) observed that music plays a key role in the lives of most people, especially adolescence, and is frequently used to manipulate emotions and modes.

Music industry also promotes economic and environmental sustainability (Cuesta, 2011; Hallam, 2015; Holt, 2010; Ogunrinade, 2015; Riall, 2011). In Georgia for instance, Riall (2011) estimated that the music industry supports almost $\$ 3.8$ billion in economic output, compensating 19,955 employees with over $\$ 888$ million in wages, salaries, and benefits. In Nigeria, statistics shows that the record sales in 1981 was about 4.5 million; in 1986 it was 5.5 million; in 1991, 8.5 million and in 1995, 12 million records were sold nationwide (Gronow \& Saunio, 1998). Environmentally, music has been used to advance advocacy towards environmental sustainability (Allen, 2012; Olusegun \& Rachel, 2017; Publicover et al., 2018, 2019; Rees, 2016; Silvers, 2015). 
Although loud music sounds have been acknowledged to have adverse effects on the occupants of buildings (Alves et al., 2015; Challe, 2015; Silva, 2015; Treasure, 2012) listening to soothing music reduces stress, blood pressure, depression, anxiety and post-operative trauma when compared to silence (Iyendo, 2016; Keller, 2019; Laura et al., 2015; Raglio et al., 2020). Unequivocally, the first step towards sustainability of our buildings is to care for our society that is full of vibrant ecosystems and that we must work together to preserve (Challe, 2015). This is even more important in residential buildings where we spend most of our time (Aletta \& Kang, 2018, 2019; Marques \& Pitarma, 2018; Wilson, 2017).

Implicitly, residential buildings need to be acoustically sustainable regardless of the makeups and nature of buildings. A recent study on the acoustic performance residential buildings in Awka Anambra shows that the overall acoustic performance of the building was grossly poor and unsatisfactory with high level of residents' dissatisfaction (Okoye et al., 2020a). Music has been found to improve the socioecological indoor environment of a building (Challe, 2015; Jiang et al., 2019; Petocz et al., 2014; Titon, 2009a). Yet, the roles of music sounds towards acoustically sustainable buildings have not been adequately explored. According to Kang and Aletta (2015) and Aletta et al., (2016), pursuit towards quietness and silence is not always the best option in all cases of high quality acoustic environment. On this premise, this study examines the socioecological roles of music sounds in achieving acoustically sustainable residential buildings.

\section{Literature review}

As an emerging area of discipline, ecomusicology or ecocritical musicology considers the interconnections between music, nature, and culture, including between non-human sound worlds and human sound worlds (Garett, 2013). It also reflects the overlap of the physical and cultural environments as mediated through sound (Allen et al., 2014). In this regard, Taylor \& Hurley (2015) found acoustic ecology and ecomusicology as one of the five contemporary and emerging fields of interest that connect music and environment. Taylor \& Hurley (2015) also acknowledge the increase of the studies on the intersections of the two concepts, particularly as composers, performers, and musicologists attempt to respond to matters of climate change, sustainability, and environmental collapse in novel and meaningful ways. Relatively, the design for sustainable buildings should equally consider acoustical concerns from standpoints of efficiency, productivity, functionality, health, comfort and environmental impacts (Celiskan \& Arslan, 2005). In this case, the soundscape shapes the aural dimension of the landscape; and it's the aural 'space' shared by humans, human technologies, and the natural world (Rothenberg, 2016; Titon, 2009b; Wolcott, 2016).

Although there are very few studies in this area of study, the growing scientific acknowledgement of music's ability to elicit physiological, psychological, and cognitive responses and entertainment, so as to evoke imagery and associations that seem to be unique for each individual has been noted (Batt-Rawden \& Storlien, 2019). Thus, van der Hoeven \& Hitters (2019) revealed that there are both social (social capital, public engagement and identity) and cultural values (musical creativity, cultural vibrancy and talent development) of urban music ecology which can be supported through specific cultural policies and urban planning interventions. Titon (2009b) opines that studies about ecomusicology should consider music's direct impact on the environment and flow of music and sound in the environment, rather than how musical compositions represent the environment. However, environmental movement in 
music is typically associated with the folk music genre, mostly because as an acoustic musical style, it lends itself well to conveying environmental messages through the lyrics (Challe, 2015). But beyond the frontiers of mere entertainment activity, music performances geared more towards socio-cultural dimensions due to its ability to socialise, consolidate values and other utilitarian exigencies (Ojukwu et al., 2016).

Many studies have demonstrated how sound environment can influence the peoples' behaviours positively and negatively (Aletta et al., 2016; Franěk et al., 2014; Meng \& Kang, 2013; Miedema, 2004; Ren \& Kang, 2015), despite the depiction of sound as noise is often subjective and it can vary across individuals (Murphy \& King, 2014). According to Meng et al. (2018), sound environment can affect human perception, and human perception can influence individual and crowd behaviour in both indoor and outdoor spaces. Literature survey also found that music sounds are usually continuous and if not controlled could have physical and mental health effects, psychological and non-auditory effects, and physiological and auditory effects (Basner et al., 2014).

Understandably, poor indoor environmental quality adversely affects the performance and health of building users (Bughio et al., 2020). Research also showed that poor acoustic performance including music, can have a negative impact on health, behaviour and cognitive function (Alves et al., 2015; Challe, 2015; Emenike \& Sampson, 2017; Hodgson, 2008; Schmidt et al., 2019; Murphy \& King, 2014; Nurzyński, 2005; Nyoni, 2015; Oloruntoba et al., 2012; Silva, 2015; The Department of Health, 2018; Treasure, 2012; WHO, 2011, 2018), due to lack of awareness of how poor acoustic quality affects us and to total lack of understanding of acoustic as an integral part of either aesthetics or functionality of a building (Wilson, 2017). Okoye et al. (2020b) even found that that undirected loud music sounds severely affect the sustainability performance of buildings socially, environmentally, economically and technically.

Nevertheless, a trial study conducted by Raglio et al. (2020) suggested that daily listening to music could reduce work-related stress at home and that the effect may be related not only to individual musical preferences and familiarity, but also to specific music structure and parameters. Fundamentally, the goal of sustainable building is to create buildings that preserve the environment and conserve natural resources, as well as to provide a 'healthy' environment for its occupants (Hodgson, 2008). A healthy environment is one that does not cause disease, promotes well-being and, in the case of places for work and learning (i.e. schools), promotes productivity (Hodgson, 2008). Therefore, music sound is important indicator for social sustainability aspects of buildings when considering the importance of health and wellbeing of persons inhabiting a building (Dolezal \& Spitzbart-Glasl, 2015).

A study conducted to examine the effects of music over the quality of the public urban experience of park users by Steele et al. (2019), by allowing users to play audio content from personal devices over publicly provided speakers revealed positive outcomes both at the individual level (in terms of soundscape evaluations and mood benefits) and at the social level (in terms of increased interaction and lingering behaviours). The study further revealed that the park was perceived as more pleasant and convivial for both users and non-users, and the perceived soundscape calmness and appropriateness was not affected. Sequel to this, Aletta and Kang (2019) argue that "non-quiet spaces might still have the potential to promote positive user 
experiences of an urban environment or that quietness cab not necessarily always match less loud acoustic environments".

A proposed model to predict urban vibrancy using soundscape approach by Aletta and Kang (2018) indicated that the perceived vibrancy can be predicted by the presence of music in the auditory scene among other parameters. This therefore implies that music is an important component of modern urban soundscape, and has the capacity to promote social experience of a place (Aletta \& Kang, 2019). Taghipour et al. (2019)investigated acoustic comfort in virtual inner yards with various building facades and found that façade absorption generally increases acoustic comfort, but too much absorption was not helpful. The study further found that pleasant and unpleasant sounds were associated with comfort and discomfort respectively. By implication, music as a pleasant sound is likely to promote comfort in the inner parts of a building. A recent study conducted by Jo and Jeon (2020) on the effect of the appropriateness of the sound environment on urban soundscape perception revealed that human sounds originating from human activity were related to the comfort aspect of soundscape quality.

Another study by Yi and Kang (2019) revealed that background music can increase individuals' positive evaluation of environment, facilitate approach behaviour, and enhance pleasure and dominance emotions, whereas foreground music can increase arousal distinctly. Similarly, Jiang et al. (2019) revealed that music creates a more positive sound environment which can be used to change the indoor sound environment and regulates people's interactive behaviour and dialogue quality. Batt-Rawden and Storlien (2019) also found that using music as an environmental intervention in nursing homes improves interaction, communication, and development of care with patients. Generally, there is consensus among the scholars and practitioners that music influences the body, mind, and spirit (Batt-Rawden \& Storlien, 2019). It is on this basis that Ratcliffe (2019) provided a theoretical explanation on why certain sounds are perceived positively so as to integrate available evidence into wider work on environment and wellbeing, similar to classical theories of music, mood and movement espoused by Murrock and Higgins (2009).

Thus, with increasing urbanisation as well as increase in soundscape around residential areas, it becomes obvious that most residential buildings around urban centres show low sound attenuation due to ineffective insulation of the components of buildings (Okoye et al., 2020b). A condition related to the non-consideration of acoustic criteria in the building designs and construction (Park et al., 2017), unlike in the advanced countries (Zalejska-Jonsson, 2019). Therefore, this study builds on the existing studies to examine the socioecological roles of music sounds in achieving acoustically sustainable residential buildings. On this ground, the following hypotheses are raised to give further direction to this study. First hypotheses, music does not influence the acoustical sustainability performance of residential buildings. Second hypotheses, there is no significant difference between the opinions of residents of the three urban centres in Anambra State regarding the roles of music towards acoustically sustainable residential buildings.

\section{Methodology}

The study followed the same survey research approach and procedure as Okoye et al. (2020b), where questionnaires were administered to the occupants of residential buildings in the three urban centres i.e. Awka, Onitsha and Nnewi in Anambra State. These urban centres 
have witnessed increased volume of residential buildings and human activities due to their socioeconomic condition in the state. The researchers used selected sample from the population to discover the relative statistical distribution of selected sample, of the population. The population for this study comprises all the residents of the three urban centres.

The questionnaire was designed to examine the socioecological roles of music sounds in achieving acoustically sustainable residential buildings in the three urban centres of Anambra State Nigeria. The questionnaire consisted of two parts. Part 1 captured the respondents' demographic data (place of living, nature of occupant, type of building, age of respondents, frequency of use of music sounds and time of use of music). Part 2 contained 29 items measuring the socioecological roles of music sounds in achieving acoustically sustainable residential buildings. The respondents were asked to express their opinions and observations based on their experiences and perceptions on the questions regarding the effects of pleasant music on the occupants of residential buildings as extracted variables from the literature on a 5-point scale, where 1 = strongly disagreed, $2=$ disagreed, $3=$ neutral, $4=$ agreed, $5=$ strongly agreed.

The population of Awka, Nnewi and Onitsha were 143,660, 233,658 and 261,604 in 2006 respectively (NPC, 2009; UN-Habitat, 2009a, 2009b, 2009c). Although there was observed disparity in the growth rate of population in these turban centres; the national average population growth rate recommended for Anambra State for population projections and had been used by Anambra State Bureau of Statistics (2012) and UN-Habitat (2009a, 2009b, 2009c), was $2.83 \%$. Therefore, in 2019, Awka, Nnewi and Onitsha populations would have been increased exponentially to $211,880,337,566$ and 377,940 respectively, based on the Malthusian growth model given in Equation 1.

$$
P_{n}=P_{0} e^{r t}
$$

Where $P_{0}$ denotes the initial (base year) population;

$P_{\mathrm{n}}$ denotes Population in the current year (required population);

$r$ denotes the growth rate $=2.83 \%(0.0283)$ (i.e. average population growth rate of Anambra State); and

$t$ denotes the time interval (years) $=13$ years.

In this case, the total population of the study was 927,386. To determine the sample size, Israel (1992) suggested different ways including; census for a small population, sample size of a similar study, published table, and the use of formulas. In this case, a familiar study has been carried out by Okoye et al. (2020b). Thus, the same sample size of 384 would be adopted for the current study in its entirety. Proportionately, the sample size for the three urban centres was also 88 for Awka, 140 for Nnewi, and 156 Onitsha.

The survey also adopted a multi-stage sampling procedure in selecting the desired samples (respondents), where a proportional stratified sampling was firstly used to subdivide the samples into 3 sub-groups. This is followed by stratified sampling technique for selecting the building in which the respondents occupy based on some specified criteria. Lastly, a simple random sampling technique was used in choosing the respondents within the selected buildings. The following criteria were considered must be met for one to be included in the survey. First, the person must be an adult. Second, live in or occupy a building situated in any of the three centres. The last, a maximum of three respondents per building. 
In all, 30, 47 and 52 buildings making a total of 129 were selected from Awka, Nnewi, and Onitsha respectively. Since this study followed the pattern of the authors' earlier study in the study area, there was already established familiarisation which made the distribution and retrieval of the questionnaire easier. Expectedly, questionnaires were administered to 384 occupants of residential buildings in the three study urban centres. Through constant contacts with the respondents, all the questionnaires were retrieved, and only 7 were found to be invalid and subsequently discarded for either not being properly filled or returned empty. The remaining 377 comprising 88 from Awka, 138 from Nnewi and 151 from Onitsha, representing about $98.18 \%$ were found to be adequate and suitable for use for analysis.

The data generated through the questionnaire were descriptively and quantitatively analysis. The socioecological roles of music sounds in achieving acoustically sustainable residential buildings were evaluated using Mean Score Index (MSI). Thereafter, one-way ANOVA was used to establish the significance of the influence of music sounds on the sustainability performance of buildings in the study area. The same ANOVA test was also performed to determine the significance of the difference between the opinions of the residents of the three urban centres in Anambra State regarding the roles of music towards acoustically sustainable residential buildings. These computations were done with the use of SPSS software.

To ensure reliability of the result, the margin of error was computed at $95 \%$ confidence interval (C.I) within which the result would be acceptable. Usually, the critical value is expressed as a t-statistic. In this case, it would be the t-statistic having 383 degrees of freedom and a cumulative probability equal to 0.975 . From the t-Distribution, the critical value is found to be 1.96. Thus, the result of this study is reliable and acceptable within $+/-5 \%$-point margin of error, and at the 95\% confidence level. This is in line with Data Star (2008) which suggested that an acceptable margin of error used by survey researchers falls between $4 \%$ and $8 \%$ at the $95 \%$ confidence level. Bartlett et al. (2001) also recommended $+/-5 \%$-point margin of error for this kind of data.

\section{Result and discussion}

\subsection{Analysis of demographic information}

Table 1 showed the demographic information about the respondents. It was revealed that the respondents were made up of $64.99 \%$ of male and $35.01 \%$ of female. Out of this number, $28.91 \%$ were aged between $18-30$ years, $44.83 \%$ were aged between $31-40$ years, $15.12 \%$ were aged between $41-50$ years, $5.57 \%$ were aged between $51-60$ years, and the same $5.57 \%$ were aged above 60 years. Likewise, $28.65 \%$ were single, $66.58 \%$ were married, whereas, $4.77 \%$ were either widow or widower. About $25.20 \%$ of the respondents were either student or apprentice, $35.01 \%$ ) were employed, $29.71 \%$ were self-employed, while $10.08 \%$ were either unemployed or retired.

Table 1 also revealed that majority of the respondents were lettered to at least up to primary school level (98.14\%), while an insignificant number of about (1.86\%) had no formal education. This indicated that the respondents were educated and can understand the basis of the study and at the same time provide the necessary information and responses required for the study. Equally, greater percentage $(82.49 \%)$ of the respondents were living in a rented apartment or building, and do not own the building they are living in while $17.51 \%$ owned the building they are living in. It also showed that majority of the respondents (78.25\%) were living 
Table 1. Demographic information

\begin{tabular}{|c|c|}
\hline Variable & Responses (\%) \\
\hline \multicolumn{2}{|l|}{ Sex distribution } \\
\hline Male & 64.99 \\
\hline Female & 35.01 \\
\hline \multicolumn{2}{|l|}{ Age distribution } \\
\hline 18-30 years & 28.91 \\
\hline $31-40$ years & 44.83 \\
\hline $41-50$ years & 15.12 \\
\hline $51-60$ years & 5.57 \\
\hline Above 60 years & 5.57 \\
\hline \multicolumn{2}{|l|}{ Marital status } \\
\hline Single & 28.65 \\
\hline Married & 66.58 \\
\hline Widow/widower & 4.77 \\
\hline \multicolumn{2}{|l|}{ Educational level } \\
\hline No Formal Education & 1.86 \\
\hline Primary & 13.00 \\
\hline Secondary & 41.11 \\
\hline Tertiary & 44.03 \\
\hline \multicolumn{2}{|l|}{ Employment status } \\
\hline Student/Apprentice & 25.20 \\
\hline Employed & 35.01 \\
\hline Self employed & 29.71 \\
\hline Unemployed/Retired & 10.08 \\
\hline \multicolumn{2}{|l|}{ Occupancy status } \\
\hline Owner occupied & 17.51 \\
\hline Tenant occupied & 82.49 \\
\hline \multicolumn{2}{|c|}{ Number of family occupancy } \\
\hline Single family & 21.75 \\
\hline Multi family & 78.25 \\
\hline \multicolumn{2}{|l|}{ Type of residential building } \\
\hline Bungalow & 7.16 \\
\hline Block of flats & 60.74 \\
\hline Duplex & 22.55 \\
\hline Self-contained & 2.65 \\
\hline Detached / Semi-detached & 6.90 \\
\hline \multicolumn{2}{|l|}{ Period of occupancy } \\
\hline $1-5$ years & 7.96 \\
\hline $6-10$ years & 21.49 \\
\hline $11-20$ years & 46.15 \\
\hline Above 20 years & 24.40 \\
\hline \multicolumn{2}{|l|}{ Frequency of play of music } \\
\hline Rarely & 1.33 \\
\hline Remotely & 5.04 \\
\hline Occasionally & 62.07 \\
\hline Frequently & 31.56 \\
\hline \multicolumn{2}{|l|}{ Mostly time of play of music } \\
\hline Morning & 33.42 \\
\hline Afternoon & 2.39 \\
\hline Night & 50.93 \\
\hline All of the above & 13.26 \\
\hline
\end{tabular}


in a multi-family building while about $21.75 \%$ were living in single family buildings. This implied that the residential buildings sampled were mainly multiple-family block of flats and singlefamily duplexes, which of course, are the dominant housing types in the three urban centres in Anambra State.

In terms of the type of residential building the respondents are occupying, 7.16\% were living in bungalows, $60.74 \%$ in block of flats, $22.55 \%$ were living in duplexes, $2.65 \%$ in selfcontained, while about $6.90 \%$ were living in detached and semi-detached buildings. This implies that block of flats and duplexes are the commonest type of residential buildings in Anambra State. This is not unconnected with the changing status and the nature of the greater residents of the urban centres. In the case of the period of time the respondents have either lived or occupied the buildings, $7.96 \%$ indicated that they have lived in their buildings for between 1-5 years, $21.49 \%$ for $6-10$ years, $46.49 \%$ for $11-20$ years, and $24.40 \%$ said that they have lived in their buildings for more than 20 years. This also showed that the respondents could be able to give information on what happens to the buildings and the building performance having lived and occupied the buildings for a considerable number of years.

It was on this note that they were asked how often they play music while at home? Thus, negligible percentage of $1.33 \%$ indicated that they rarely play music while at home. $5.05 \%$ showed that they remotely play music, whereas more than half of the respondents indicated that the occasionally play music. However, $31.56 \%$ of the respondents signified that frequently play music at home. A further probe on the most probable time of play of music showed that $33.42 \%$ chose morning time, $2.39 \%$ preferred afternoon time, about half of the respondent indicated that they play music at home at the night time, while $13.26 \%$ chose any time of the day. This suggested that that majority would like to listen to music when they were relaxing at home at night as against when they are at work during the day. It also suggested that playing music at home was for a purpose instead of indiscriminately.

\subsection{Analysis of socioecological roles of music towards acoustically sustainable building}

Table 2 revealed the mean score index and standard deviation of the respondents' responses on the roles of music sounds towards acoustically sustainable building performance. The result showed that the average mean score index of the responses from Awka was 4.32 while the standard deviation was 1.099. The average mean scores from Nnewi and Onitsha were 4.33 and 4.42 respectively, while their standard deviations were 0.769 and 0.721 respectively. It further showed that the overall average mean score index was 4.36, and a range of 3.64 to 4.87 . It is an indication a concordant agreement between the residents of the three urban centres in Anambra State. Also the result indicated that music has the tendency of improving the acoustic performance of residential buildings, it can be reduced from the mean score index, that the six most prominent roles played by music towards acoustically sustainable building performance were: enabling pleasant sound environment (4.87), improving quality of relaxation and resting (4.83), increasing acoustic comfort and satisfaction (4.79), reducing depression and anxiety (4.68), and improving quality of life (4.68). The implication of this result is that music has a multidimensional role that extended beyond mere entertainment up to conditioning of internal socioecological environment of a building, medicine, health and general well-being of people. 
Table 2. Result of the MSI, standard deviation of the respondents' responses on the socioecological roles

\begin{tabular}{|c|c|c|c|c|c|c|c|c|}
\hline \multirow[t]{2}{*}{$\mathrm{S} / \mathrm{N}$} & \multirow[t]{2}{*}{ Socioecological Variables } & \multicolumn{2}{|c|}{$\begin{array}{c}\text { Awka } \\
(\mathrm{N}=88)\end{array}$} & \multicolumn{2}{|c|}{$\begin{array}{c}\text { Nnewi } \\
(\mathrm{N}=138)\end{array}$} & \multicolumn{2}{|c|}{$\begin{array}{l}\text { Onitsha } \\
(\mathrm{N}=151)\end{array}$} & \multirow{2}{*}{$\begin{array}{l}\text { Overall } \\
\text { MSI }\end{array}$} \\
\hline & & MSI & Std. D. & MSI & Std. D. & MSI & Std. D. & \\
\hline 1 & $\begin{array}{l}\text { Reducing emotional and } \\
\text { work-related stresses }\end{array}$ & 4.78 & .414 & 4.67 & .470 & 4.60 & .613 & 4.67 \\
\hline 2 & $\begin{array}{l}\text { Promoting health and well- } \\
\text { being of occupants }\end{array}$ & 3.73 & .620 & 3.86 & .901 & 4.14 & .721 & 3.94 \\
\hline 3 & $\begin{array}{l}\text { Maintaining a high level } \\
\text { satisfaction and moral health }\end{array}$ & 3.48 & .711 & 3.51 & .938 & 3.85 & .919 & 3.64 \\
\hline 4 & $\begin{array}{l}\text { Reduces emotional and } \\
\text { physical trauma }\end{array}$ & 4.49 & .503 & 4.57 & .540 & 4.56 & .498 & 4.55 \\
\hline 5 & $\begin{array}{l}\text { Promoting positive } \\
\text { occupants' experiences }\end{array}$ & 3.88 & .708 & 3.71 & 1.005 & 4.19 & .716 & 3.94 \\
\hline 6 & $\begin{array}{l}\text { Reducing depression and } \\
\text { anxiety }\end{array}$ & 4.57 & .498 & 4.71 & .455 & 4.72 & .450 & 4.68 \\
\hline 7 & Reducing blood pressure & 4.23 & .723 & 3.55 & .811 & 3.60 & .713 & 3.73 \\
\hline 8 & $\begin{array}{l}\text { Increasing acoustic comfort } \\
\text { and satisfaction }\end{array}$ & 4.89 & .319 & 4.78 & .431 & 4.74 & .439 & 4.79 \\
\hline 9 & $\begin{array}{l}\text { Increasing individuals' } \\
\text { positive evaluation of indoor } \\
\text { environment }\end{array}$ & 4.53 & .502 & 4.54 & .501 & 4.63 & .485 & 4.57 \\
\hline 10 & $\begin{array}{l}\text { Enhancing pleasure and } \\
\text { dominance emotions }\end{array}$ & 4.06 & .701 & 4.33 & .606 & 4.38 & .513 & 4.28 \\
\hline 11 & $\begin{array}{l}\text { Regulating of people's } \\
\text { interactive and } \\
\text { communicative behaviour }\end{array}$ & 4.58 & .496 & 4.51 & .570 & 4.55 & .499 & 4.54 \\
\hline 12 & Improving dialogue quality & 3.60 & .653 & 4.09 & .867 & 4.44 & .498 & 4.11 \\
\hline 13 & $\begin{array}{l}\text { Improving quality of } \\
\text { relaxation and resting }\end{array}$ & 4.83 & .378 & 4.90 & .303 & 4.77 & .439 & 4.83 \\
\hline 14 & $\begin{array}{l}\text { Diminishing unpleasant } \\
\text { noise effects }\end{array}$ & 4.75 & .435 & 4.59 & .494 & 4.66 & .475 & 4.66 \\
\hline 15 & $\begin{array}{l}\text { Enhancing indoor mental } \\
\text { picture }\end{array}$ & 4.45 & .677 & 4.40 & .548 & 4.28 & .715 & 4.37 \\
\hline 16 & $\begin{array}{l}\text { Reducing indoor sick } \\
\text { building syndrome effect }\end{array}$ & 4.47 & .710 & 4.25 & .820 & 4.11 & .868 & 4.25 \\
\hline 17 & Improving indoor air quality & 3.72 & .454 & 4.07 & .642 & 4.48 & .501 & 4.15 \\
\hline 18 & Reducing over-boringness & 4.67 & .473 & 4.62 & .488 & 4.66 & .477 & 4.64 \\
\hline 19 & Reducing the pain of sickness & 3.55 & .870 & 3.75 & .818 & 3.85 & .964 & 3.74 \\
\hline 20 & Improving quality of life & 4.58 & .496 & 4.64 & .480 & 4.78 & .430 & 4.68 \\
\hline 21 & $\begin{array}{l}\text { Enabling pleasant sound } \\
\text { environment }\end{array}$ & 4.83 & .378 & 4.86 & .346 & 4.91 & .281 & 4.87 \\
\hline $\begin{array}{l}\text { Total } \\
\text { Devia }\end{array}$ & $\begin{array}{l}\text { erage MSI and Standard } \\
\text { n }\end{array}$ & 4.32 & 1.099 & 4.33 & .769 & 4.42 & .721 & 4.36 \\
\hline
\end{tabular}

To give further confidence to the results of this study, the earlier stated hypotheses were analysed. The results of the analyses are presented in Tables 3 and 4.

\subsection{Test of hypothesis}

The result of Table 3 showed that the $p$-value (.000) is lesser than the Alpha $\alpha(0.05)$ which an indication that F-ratio (148.377) value is greater than F-critical (3.020). In this case, the null hypothesis is rejected, and a conclusion that music significantly influences acoustical 
sustainability performance of residential buildings. This further implied that music sounds significantly play socioecological roles towards attaining acoustical sustainability performance in residential buildings in Anambra State. This is aligned with the value of the overall average mean score index (4.36) presented in Table 2.

Table 3. ANOVA result for hypothesis one.

\begin{tabular}{lccccccc}
\hline \multicolumn{1}{c}{ Sources } & & Sum of Squares & df & Mean Square & F-Ratio & p-value & Decision \\
\hline Between People & & 273.677 & 376 & 0.728 & & & \\
Within People & Between Items & 1142.694 & 20 & 57.135 & 148.377 & 0.000 & Reject $\mathrm{H}_{0}$ \\
& Residual & 2895.686 & 7520 & 0.385 & & & \\
& Total & 4038.381 & 7540 & 0.536 & & & \\
Total & & 4312.058 & 7916 & 0.545 & & & \\
\hline
\end{tabular}

Grand Mean $=4.36 ;$ F-critical $=3.020 ; \alpha=.05$

Table 4. ANOVA result for hypothesis two.

\begin{tabular}{lcccccc}
\hline \multicolumn{1}{c}{ Sources } & Sum of squares & df & Mean squares & F-Ratio & $\boldsymbol{p}$-value & Decision \\
Between group & 0.809 & 2 & 0.404 & 0.338 & .713 & Accept $\mathrm{H}_{0}$ \\
Within group & 264.527 & 374 & 1.196 & & & \\
Total & 265.336 & 376 & & & & \\
\hline Grand Mean $=4.36 ;$ F-critical $=3.020 ; \alpha=.05$ & & & & \\
\hline
\end{tabular}

The result of Table 4 showed that the $p$-value (.713) is greater than the Alpha $\alpha(0.05)$. This is an indication that F-ratio (0.338) value is lesser than F-critical (3.020). In this case, the null hypothesis was accepted, and a conclusion was reached that there is no significance difference between the opinions of residents of the three urban centres in Anambra State regarding the roles of music towards acoustically sustainable residential buildings. The implication is that music has the same socioecological influence on the residents of the three urban centres in Anambra State when it comes to applying music to stabilising indoor environmental quality of residential buildings. This further affirmed the result of hypothesis one which stated that music sounds as experienced by the residents of the three urban centres in Anambra State influence the acoustical sustainability performance of residential buildings.

Thus, the overall results of this study indicated that music sound plays a vital role in promoting the acoustical sustainability performance of residential buildings through many ways such as enabling pleasant sound environment, improving quality of relaxation and resting, increasing acoustic comfort and satisfaction, reducing depression and anxiety, improving quality of life, etc. The results also showed general consensus among the residents of the three urban cities of Anambra State on the roles played by the music sounds towards socioecological sustainability. However, the study revealed that music is occasionally played at home mainly for specific and different purposes, but in most case at night and in the morning. These periods correspond to the periods when people are mostly found at home.

Furthermore, this study has affirmed that not all forms of sound could have a deleterious effect on occupants of a building, rather a soothing music has a poignant effect which should be harnessed for the overall benefits of the building occupants. Significantly, this study has shown that music has great potentials in reducing noise within a building, and thereby neutralising the negative consequences of noise on building occupants. This position is in line with the advocacy 
being promoted by Treasure (2012) through proactively using music sound to lower stress levels and create a more positive environment.

The result of this study therefore is in line with that of Dolezal and Spitzbart-Glasl (2015) who found that acoustic quality of building components can have impact on the ecological performance of the whole building. Backed by the classical theories of music, mood and movement championed by Murrock and Higgins (2009), this study keyed into the results of other studies (Batt-Rawden \& Storlien, 2019; Challe, 2015; Jiang et al., 2019; Jo \& Jeon, 2020; Raglio et al., 2020; Yi \& Kang, 2019) that affirmed the positive roles of music towards ensuring socioecological sustainability and promoting the well-being of building users in our buildings. The study has strengthened the result of Okoye et al. (2020b) which found that among the sustainability dimensions, social sustainability performance of buildings was mostly affected, but in the antithetical direction.

\section{Conclusion}

Fundamentally, a residential building is to offer its occupants a conducive, safe, comfortable, healthy and secured indoor environment that would enable him to perform his different forms of activities at home including leisure, family life and social interactions for overall improvement of quality of life. However, the rising cases of noisy environment within our living areas in the emerging urban centres in addition to poor acoustic performance of our residential buildings and the general notion that music sound in all its entirety is noise has call for more insight into the roles of music towards acoustically sustainable building performance in our urban centres. Although not ranked at the same level as building itself in the hierarchy of human needs, this study has demonstrated that music plays a crucial role in the socio-cultural life of building occupants. Therefore, this paper has established the link between music acoustics this study found that despite the negative implications of uncoordinated loud music sounds, music promotes socioecological sustainability and indoor environmental quality of residential buildings through many ways.

This study has further established that music sounds have significance influence on the acoustical sustainability performance of residential buildings. Even among the residents of the three urban centres in Anambra State, there was a consensus agreement that music has significance influence on the acoustical sustainability performance of residential buildings. Implicitly, the result of this study has shown that application of music goes beyond mere entertainment to building sustainability and general well-being of people occupying the building.

Having seen the importance of music in modelling the socioecological indoor environment of a building, there is need for adjustment and readjustment in the current building design and construction practices to accommodate the intrinsic and extended benefits of music in our buildings for the optimal well-being of the occupants especially the residential buildings where we spend most parts of our time. This implies that the underlying principles of ecomusicology and sustainable building should be integrated in the general building practices to generate an acoustically sustainable building. Since building designs considering music acoustics and music principles are absent, this study suggested that integrating music principles and acoustics into sustainable design process is a way of achieving a sustainable building. It therefore, entails the need for review in the existing routes and frameworks of building industry professionals' practices to incorporate music acoustics in the curriculum through which this integration could 
be naturally enabled. This study is also a reawakening call to the building industry players and professionals towards abridging their knowledge to incorporate this aspect of sustainability in their practices. There is also need to revisit and strengthen all existing Building Codes to ensure adequate coverage of all aspect of acoustics in building practice and performance.

\section{References}

Aletta, F., \& Astolfi, A. (2018). Soundscapes of buildings and built environments. Building Acoustics, 25(3), 195-197. http://doi.org/10.1177/1351010X18793279

Aletta, F., Botteldooren, D., Thomas, P., Mynsbrugge, T. Vander, Vriendt, P. De, Velde, D. Van de, \& Devos, P. (2017). Monitoring Sound Levels and Soundscape Quality in the Living Rooms of Nursing Homes: A Case Study in Flanders (Belgium). Applied Science, 7(9), 874. http://doi.org/10.3390/app7090874

Aletta, F., \& Kang, J. (2018). Towards an Urban Vibrancy Model: A Soundscape Approach. Int. J. Environ. Res. Public Health, 15(8), 1712. http://doi.org/10.3390/ijerph15081712

Aletta, F., \& Kang, J. (2019). Promoting Healthy and Supportive Acoustic Environments: Going beyond the Quietness. Int. J. Environ. Res. Public Health, 16(24), 4988. http://doi.org/10.3390/ijerph16244988

Aletta, F., Lepore, F., Kostara-Konstantinou, E., Kang, J., \& Astolfi, A. (2016). An Experimental Study on the Influence of Soundscapes on People's Behaviour in an Open Public Space. Applied Science, 6(10), 276. http://doi.org/10.3390/app6100276

Allen, A., \& Dawe, K. (2016). Current discussion in Ecomusicology: Music, culture, nature. New York: Routledge.

Allen, A. S. (2012). Ecomusicology: music, culture, nature ... and change in environmental studies? Journal of Environmental Studies and Sciences, 2, 192-201. http://doi.org/10.1007/s13412-012-0072-1

Allen, A. S., Titon, J. T., \& Glahn, D. V. (2014). Sustainability and sound: ecomusicology inside and outside the academy. Music and Politics, 8(2), 1-20. http://doi.org/10.3998/mp.9460447.0008.205

Alves, J. A., Silva, L. T., \& Remoaldo, P. C. C. (2015). The Influence of Low-Frequency Noise Pollution on the Quality of Life and Place in Sustainable Cities: A Case Study from Northern Portugal. Sustainability, 7(10), 13920-13946. http://doi.org/10.3390/su71013920

Anambra State Bureau of Statistics. (2012). 2011 Statistical Year Book. Ministry of Economic planning and Budget, Awka. Retrieved from https://www.nigerianstat.gov.xn-ngpdfuploadsstatisticalyearbook2009-ey2vka

Barbaroux, M., Dittinger, E., \& Besson, M. (2019). Music training with Démos program positively influences cognitive functions in children from low socio-economic backgrounds. PLOS ONE, 14(5), e0216874. http://doi.org/10.1371/journal.pone.0216874

Bartlett II, J. E., Kotrlik, J. W., \& Higgins, C. C. (2001). Organizational research: Determining appropriate sample size in survey research appropriate sample size in survey research. Information Technology, Learning, and Performance Journal, 19(1), 43-50.

Basner, M., Babisch, W., Davis, A., Brink, M., Clark, C., Janssen, S., \& Stansfeld, S. (2014). Auditory and nonauditory effects of noise on health. The Lancet, 383(9925), 1325-1332. http://doi.org/0.1016/S0140-6736(13)61613-X

Batt-Rawden, K. B., \& Storlien, M. H. S. (2019). Systematic Use of Music as an Environmental Intervention and Quality of Care in Nursing Homes: A Qualitative Case Study in Norway. Medicine, 6(1), 12. http://doi.org/10.3390/medicines6010012

Bendrups, D., Barney, K., \& Grant, C. (2013). An introduction to sustainability and ethnomusicology in the Australasian context. Musicology Australia, 35(2), 153-158. http://doi.org/10.1080/08145857.2013.844470

Bughio, M., Schuetze, T., \& Mahar, W. A. (2020). Comparative Analysis of Indoor Environmental Quality of Architectural Campus Buildings' Lecture Halls and its' Perception by Building Users, in Karachi, Pakistan. Sustainability, 12(7), 2995. http://doi.org/10.3390/su12072995

Celiskan, M., \& Arslan, S. (2005). Acoustics education for sustainable buildings: METU experience. In Conference on Sustainable Buildings South-East Asia (SB04 Series). Kuala Lumpur. 
Challe, T. (2015). Ecomusicology: back to the roots of sound/music and environmental sustainability. City University of New York.

Cuesta, J. (2011). Music to my ears: The (many) socioeconomic benefits of music training programmes. Applied Economics Letters, 18(10), 915-918. http://doi.org/10.1080/13504851.2010.517187

Data Star. (2008). What every researcher should know about statistical significance. Retrieved January 15 , 2020, from https://www.surveystar.com/startips

Dolezal, F., \& Spitzbart-Glasl, C. (2015). Relevance of Acoustic Performance in Green Building Labels and Social Sustainability Ratings. Energy Procedia, 78, 1629-1634. http://doi.org/10.1016/j.egypro.2015.11.241

Eidsheim, N. S. (2015). Sensing sound. singing and listening as vibrational practice. Duke University Press.

Emenike, G. C., \& Sampson, A. P. (2017). Noise levels and quality of livelihoods in residential neighbourhoods of Port Harcourt Metropolis, Nigeria. European Journal of Earth and Environment, 4(1), 19-28.

Franěk, M., Noorden, L. van, \& Režný, L. (2014). Tempo and walking speed with music in the urban context. Frontiers in Psychology, 5, 1361. http://doi.org/10.3389/fpsyg.2014.01361

Garett, G. H. (2013). The grove dictionary of American music (Second Edi). Oxford: Oxford University Press.

Gronow, P., \& Saunio, I. (1998). International History of the Recording Industry. London and New York: Cassel.

Hallam, S. (2015). The power of music: A research synthesis of the impact of actively making music on the intellectual, social and personal development of children and young people. London: Music Education Council.

Hawkes, J. (2001). The Fourth Pillar of Sustainability. Culture's essential in Public Planning. Victoria: Common Ground Publishing Pty Ltd.

Hodgson, M. (2008). Acoustical Evaluation of Six “Green” Office Buildings. Journal of Green Building, 3(4), 108-118.

Holt, F. (2010). The economy of live music in the digital age. European Journal of Cultural Studies, 13(2), 243-261. http://doi.org/10.1177/1367549409352277

Israel, G. D. (1992). Determining sample size. Florida: University of Florida.

Iyendo, T. O. (2016). Exploring the effect of sound and music on health in hospital settings: A narrative review. International Journal of Nursing Studies, 63, 82-100. http://doi.org/10.1016/j.ijnurstu.2016.08.008

Jahangeer, F. (2019). Acoustic comfort in the living environment and its association with noise representation: A systematic review. In 14th European Architecture Envisioning Conference (EAEA14 2019) SHS Web Conf. Volume 64 (p. 3012). http://doi.org/10.1051/shsconf/20196403012

Jesper Hvass Schmidt, Paarup, H. M., \& Bælum, J. (2019). Tinnitus severity is related to the sound exposure of symphony orchestra musicians independently of hearing impairment. Ear and Hearing, 40(1), 8897. http://doi.org/10.1097/AUD.0000000000000594

Jiang, J., Li, N., Meng, Q., \& Kang, J. (2019). The Influence of Background Music on Interactive Behaviour in an Indoor Space. In In INTER-NOISE and NOISE-CON Congress and Conference Proceedings (pp. 58665876). Madrid: Institute of Noise Control Engineering.

Jo, H. I., \& Jeon, J. Y. (2020). Effect of the appropriateness of sound environment on urban soundscape $\begin{array}{llll}\text { assessment. Building and } & 106975 .\end{array}$ http://doi.org/10.1016/j.buildenv.2020.106975

Jodouin, C. (2018). A review of Mark Pedelty's Ecomusicology: Rock, Folk and the environment. Critical Voices The University of Guelph Book Review Project, 6(1), 51-57.

Kang, J., \& Aletta, F. (2015). Soundscape approach integrating noise mapping techniques: A case study in Brighton, UK. Noise Mapping, 2(1), 1-12. http://doi.org/https://doi.org/10.1515/noise-2015-0001

Keller, J. (2019). How to create a stress-reducing playlist. PsyArXiv, 1. Retrieved from https://doi.org/10.31234/osf.io/23kgu 
Laura, D., Sylvie, J., \& Aurore, S. (2015). The effect of music therapy on anxiety and depression. Annals of Depression and Anxiety, 2(4), 1057.

Marques, G., \& Pitarma, R. (2018). Indoor Air Quality Monitoring for Enhanced Healthy Buildings. In Indoor Environmental Quality. London: IntechOpen. http://doi.org/10.5772/intechopen.81478

Martin, D. (2017). Cultural value and urban governance: A place for Melbourne's music community at the policymaking table. Perfect Beat, 18(2), 110-130. http://doi.org/10.1558/prbt.32968

Meng, Q., \& Kang, J. (2013). Influence of Social and Behavioural Characteristics of Users on Their Evaluation of Subjective Loudness and Acoustic Comfort in Shopping Malls. PLoS ONE, 8(1), e54497. http://doi.org/10.1371/journal.pone.0054497

Meng, Q., Zhao, T., \& Kang, J. (2018). Influence of Music on the Behaviors of Crowd in Urban Open Public Spaces. Frontiers in Psychology, 9, 596. http://doi.org/10.3389/fpsyg.2018.00596

Miedema, H. M. E. (2004). Relationship between exposure to multiple noise sources and noise annoyance. The Journal of the Acoustical Society of America, 116, 949. http://doi.org/10.1121/1.1766305

Morimoto, M. M. (2017). Music and architecture: Notes on experiencing the convergence of music and built environment. University of Hawai'I at Mānoa. Retrieved from http://hdl.handle.net/10125/45558.

Murphy, E., \& King, E. (2014). Environmental Noise Pollution: Noise Mapping, Public Health, and Policy. Amsterdam: Elsevier.

Murrock, C. J., \& Higgins, P. A. (2009). The theory of music, mood and movement to improve health outcomes. Journal of Advanced Nursing, 65(10), 2249-2257. http://doi.org/10.1111/j.13652648.2009.05108.x

NPC. (2009). 2006 Population and Housing Census of the Federal Republic of Nigeria. National and State Population and Housing Tables, Priority Tables, I. Retrieved January 25, 2020, from www.population.gov.ng

Nurzyński, J. (2005). Sustainability and protection against noise in a building and its surroundings. In The 2005 World Sustainable Building Conference 27-29 September 2005 (pp. 1553-1560). Tokyo.

Nyoni, J. (2015). The effects of noise and excessive sound pressure levels (SPLS) on office occupants and the strategy to improve acoustic comfort in office buildings. Deakin University.

Ogunrinade, D. O. A. (2015). Music education as a pillar to sustainable development in Nigeria. Journal of Economics and Sustainable Development, 6(3), 83-86.

Ojukwu, E., Obielozie, E., \& Esimone, C. (2016). Nigerian values and contemporary popular music: a new look. OGIRISI: A New Journal of African Studies, 12, 114-129. http://doi.org/10.4314/og.v12i s1.7

Okoye, P. U., Ngwu, C., \& Ohaedeghasi, C. I. (2020). Assessment of Acoustical Performance of Residential Buildings for Sustainable Liveability and Satisfaction in Awka, Anambra State Nigeria. Asian Journal of Environment \& Ecology, 12(3), 25-37. http://doi.org/10.9734/ajee/2020/v12i330160

Okoye, P. U., Ngwu, C., Okolie, K. C., \& Ohaedeghasi, C. I. (2020). Severity of Impact of Music Acoustics on Sustainability Performance of Buildings in Anambra State Nigeria. Energy and Environmental Engineering, 7(2), 13-26. http://doi.org/10.13189/eee.2020.070201

Oloruntoba, E., Ademola, R., Sridhar, M., Agbola, S., Omokhodion, F., Ana, G., \& Alabi, R. (2012). Urban Environmental Noise Pollution and Perceived Health Effects in Ibadan, Nigeria. African Journal of Biomedical Research, 15(2), 77-84.

Olusegun, T., \& Rachel, T. O. (2017). Jimi Solanke and Ebenezer Obey's Music on Environmental Degradation and Flood Disaster in Ibadan, Nigeria. Polymath: An Interdisciplinary Arts and Sciences Journal, 7(2), 111-130.

Park, S. H., Lee, P. J., \& Lee, B. K. (2017). Levels and sources of neighbour noise in heavyweight residential buildings in Korea. Applied Acoustics, 120, 148-157. http://doi.org/10.1016/j.apacoust.2017.01.012

Petocz, P. (2019). Heritage and sustainability in early music. University of Sydney.

Petocz, P., Reid, A., \& Bennett, D. (2014). The music workforce, cultural heritage, and sustainability. International Journal of Cultural and Creative Industries, 1(6), 4-16.

Publicover, J. L., Wright, T. S., Baur, S., \& Duinker, P. N. (2018). Music as a tool for environmental education 
and advocacy: artistic perspectives from musicians of the Playlist for the Planet. Environmental Education Research, 24(7), 925-936. http://doi.org/10.1080/13504622.2017.1365356

Publicover, J. L., Wright, T. S., Baur, S., \& Duinker, P. N. (2019). Engaging with Environmental Issues as a Musician: Career Perspectives from the Musicians of the Playlist for the Planet. Popular Music and Society, 42(2), 167-187. http://doi.org/10.1080/03007766.2018.1426367

Raglio, A., Bellandi, D., Gianotti, M., Zanacchi, E., Gnesi, M., Monti, M. C., ... Imbriani, M. (2020). Daily music listening to reduce work-related stress: a randomized controlled pilot trial. Journal of Public Health, 42(1), e81-e87. http://doi.org/10.1093/pubmed/fdz030

Ratcliffe, E. (2019). Toward a better understanding of pleasant sounds and soundscapes in urban settings. Cities and Health, 1-4. http://doi.org/10.1080/23748834.2019.1693776

Rees, H. (2016). Environmental Crisis, Culture Loss, and a New Musical Aesthetic: China's "Original Ecology Folksongs" In Theory and Practice. Ethnomusicology, 60(1), 53-88. http://doi.org/10.5406/ethnomusicology.60.1.0053

Reinten, J., Braat-Eggen, P. E., Hornikx, M., Korta, H. S. M., \& Kohlrausch, A. (2017). The indoor sound environment and human task performance: A literature review on the role of room acoustics. Building and Environment, 123, 315-332. http://doi.org/10.1016/j.buildenv.2017.07.005

Ren, X., \& Kang, J. (2015). Interactions between landscape elements and tranquility evaluation based on eye tracking experiments. The Journal of the Acoustical Society of America, 2015, 3019. http://doi.org/0.1121/1.4934955

Reybrouck, M., Podlipniak, P., \& Welch, D. (2019). Music and noise: same or different? What our body tells us. Frontrier in Psychology, 10, 1153. http://doi.org/10.3389/fpsyg.2019.01153

Riall, B. W. (2011). Economic and fiscal impact analysis of the music industry in Georgia.

Rothenberg, D. (2016). Sudden music: Improvisation, sound, nature. Georgia: University of Georgia Press.

Silva, L. T. (2015). Environmental quality health index for cities. Habitat International, 45(1), 29-35. http://doi.org/10.1016/j.habitatint.2014.06.020

Silvers, M. B. (2015). Birdsong and a Song about a Bird: Popular Music and the Mediation of Traditional Ecological Knowledge in Northeastern Brazil. Ethnomusicology, 59(3), 380-397. http://doi.org/10.5406/ethnomusicology.59.3.0380

Snyder, L. L. (2019). Voicing Mother nature: Ecomusicological perspectives on gender and philosophy in Japanese Shakuhachi practice. Kent State University.

Steele, D., Bild, E., Tarlao, C., \& Guastavino, C. (2019). Soundtracking the Public Space: Outcomes of the Musikiosk Soundscape Intervention. International Journal of Environmental Research and Public Health, 16(10), 1865. http://doi.org/10.3390/ijerph16101865

Taghipour, A., Sievers, T., \& Eggenschwiler, K. (2019). Acoustic comfort in virtual inner yards with various building facades. International Journal of Environmental Research and Public Health, 16(2), 249. http://doi.org/10.3390/ijerph16020249

Taylor, H., \& Hurley, A. (2015). Music and Environment: Registering Contemporary Convergences. Journal of Music Research Online, 6, 1-18.

The Department of Health. (2018). The health effects of environmental noise. Canberra. Retrieved from https://www1.health.gov.au/internet/main/publishing.nsf/Content/A12B57E41EC9F326CA257BF 0001F9E7D/\$File/health-effects-Environmental-Noise-2018.pdf

Titon, J. T. (2009a). Economy, ecology, and music: an introduction. The World of Music, 51(1), 5-15. Retrieved from https://www.jstor.org/stable/41699860

Titon, J. T. (2009b). Music and Sustainability: An Ecological Viewpoint. The World of Music, 51(1), 119-137. Retrieved from https://www.jstor.org/stable/41699866

Treasure, J. (2012). Building in Sound. BIAMP Systems. Retrieved from https://www.thesoundagency.com/wpcontent/uploads/2018/01/Biamp_Whitepaper_Building_in_Sound.pdf

UN-Habitat. (2009a). Structure plan for Awka and satellite towns. United Nations Human Settlements 
Programme, Nairobi, Kenya. Retrieved January 25, 2020, from http://www.unhabitat.org.

UN-Habitat. (2009b). Structure plan for Nnewi and satellite towns. United Nations Human Settlements Programme, Nairobi, Kenya. Retrieved January 25, 2020, from http://www.unhabitat.org.

UN-Habitat. (2009c). Structure plan for Onitsha and satellite towns. United Nations Human Settlements Programme, Nairobi, Kenya. Retrieved from http://www.unhabitat.org.

van der Hoeven, A., \& Hitters, E. (2019). The social and cultural values of live music: Sustaining urban live music ecologies. Cities, 9, 263-271. http://doi.org/10.1016/j.cities.2019.02.015

Vardaxis, N. G., Bard, D., \& Persson Waye, K. (2018). Review of acoustic comfort evaluation in dwellingspart I: Associations of acoustic field data to subjective responses from building surveys. Building Acoustics, 25(2), 151-170. http://doi.org/10.1177/1351010X18762687

Vargas Vera, A., San Millan-Castillo, R., \& Swerdlow, A. (2019). Sound insulation design methodology: Case study on a music rehearsal room. Acoustics in Practice: International E-Journal of the European Acoustic Association (EAA), 7(1), 1-10.

WHO. (2011). Burden of disease from environmental noise. Quantification of healthy life years lost in Europe. Copenhagen: WHO Regional Office for Europe. Retrieved from https://www.euro.who.int/_data/assets/pdf_file/0008/136466/e94888.pdf

WHO. (2018). Environmental Noise Guidelines for the European Region. Denmark: WHO Regional Office for Europe. Retrieved from https://www.euro.who.int/_data/assets/pdf_file/0008/383921/noiseguidelines-eng.pdf?ua $=1$

Wilson, J. (2017). The sound of sustainability: Acoustics in high-performance design. The Building Green Report, 26(9), 1-19.

Wolcott, S. J. (2016). The role of music in the transition towards a culture of sustainability. Empowering Sustainability International Journal, 3(1), 1-9. Retrieved from https://escholarship.org/uc/item/4vx624mc

Yi, F., \& Kang, J. (2019). Effect of background and foreground music on satisfaction, behavior, and emotional responses in public spaces of shopping malls. Applied Acoustics, 145, 408-419. http://doi.org/10.1016/j.apacoust.2018.10.029

Zalejska-Jonsson, A. (2019). Perceived acoustic quality and effect on occupants' satisfaction in green and conventional residential buildings. Building, 9(1), 24. http://doi.org/10.3390/buildings 9010024

Zhisheng, L., Dongmei, L., Sheng, M., Guoqiang, Z., \& Jianlong, L. (2007). Noise impact and improvement on indoors acoustic comfort for the building adjacent to heavy traffic road. Chinese Journal of Population Resources and Environment, 5(1), 17-25. 